\title{
Emission spectra and cross-section spectra of neodymium laser glasses
}

\author{
J. FURTHNER, A. PENZKOFER \\ Naturwissenschaftliche Fakultät II - Physik, Universität Regensburg, \\ W-8400 Regensburg, Germany
}

Received 7 August; revised 15 November; accepted 3 December 1991

Amplified spontaneous emission spectra and light amplification spectra of some $\mathrm{Nd}^{3+}$ : glass rods (silicate glass Schott LG680, phosphate glasses Schott LG760 and Hoya LHG5) are measured by pulsed flashlamp excitation. The spontaneous emission distribution, the stimulated emission cross-section spectra and the excited state absorption cross-section spectra are extracted. Excited state absorption prevents laser action around $1320 \mathrm{~nm}$ for the ${ }^{4} \mathrm{~F}_{3 / 2}-{ }^{4} \mathrm{I}_{13 / 2}$ transition of $\mathrm{Nd}^{3+}$ in the investigated glasses.

\section{Introduction}

$\mathrm{Nd}^{3+}$ doped crystals and glasses are widely applied solid-state laser materials [1-6]. From the ${ }^{4} \mathrm{~F}_{3 / 2}$ upper laser level of the $4 \mathrm{f}^{3}$ electrons of the $\mathrm{Nd}^{3+}$ ions transitions occur to all levels of the ${ }^{4} \mathrm{I}_{J}$ manifold with $J=15 / 2$ (transition wavelength $\lambda \approx 1.8 \mu \mathrm{m}$ ), $J=13 / 2$ $(\lambda \approx 1.32 \mu \mathrm{m}), J=11 / 2(\lambda \approx 1.06 \mu \mathrm{m})$ and $J=9 / 2(\lambda \approx 0.88 \mu \mathrm{m}$, ground state $)$. An energy level diagram is included in Fig. 8 [2]. The $\mathrm{Nd}$ :glass lasers generally operate on the ${ }^{4} \mathrm{~F}_{3 / 2}-{ }^{4} \mathrm{I}_{11 / 2}$ transition emitting around $1.06 \mu \mathrm{m}$ where they have great importance as high power and short pulse solid-state lasers. Laser action of $\mathrm{Nd}$ :glass lasers on the ${ }^{4} \mathrm{~F}_{3 / 2}-{ }^{4} \mathrm{I}_{13 / 2}$ transition [7-9] (flashlamp pumping at room temperature) and on the ${ }^{4} \mathrm{~F}_{3 / 2}-{ }^{4} \mathrm{I}_{9 / 2}$ transition (room temperature laser pumping [10] and low temperature flashlamp pumping $[8,11,12])$ has been reported.

The luminescence linewidths of the Nd:glass laser transitions are rather broad $(\Delta \tilde{v} \approx 100$ to $200 \mathrm{~cm}^{-1}$ ) due to Stark splitting of the involved levels and inhomogeneous broadening in the glass matrix [2-6]. Laser wavelength tuning across the luminescence linewidth is readily achieved by insertion of a tuning element in the laser oscillator [13-16].

The possible laser transitions and wavelength tuning ranges depend on the effective amplification cross-section distribution $\sigma_{\mathrm{eff}}(\lambda)=\sigma_{\mathrm{em}}(\lambda)-\sigma_{\mathrm{ex}}(\lambda)$ where $\sigma_{\mathrm{em}}$ is the stimulated emission cross-section and $\sigma_{\text {ex }}$ is the excited state absorption cross-section. For the ${ }^{4} \mathrm{~F}_{3 / 2}-{ }^{4} \mathrm{I}_{11 / 2}$ transition $\sigma_{\text {eff }}$ values at the laser frequency were determined by laser threshold measurements [17-19]. Peak stimulated emission cross-sections $\sigma_{\mathrm{em}, \mathrm{P}}$ for the ${ }^{4} \mathrm{~F}_{3 / 2}-{ }^{4} \mathrm{I}_{11 / 2}[2,20-23]$ and the ${ }^{4} \mathrm{~F}_{3 / 2}-{ }^{4} \mathrm{I}_{13 / 2}[21]$ transitions were determined by measuring absorption cross-sections and applying the Judd-Ofelt model of crystal-field induced electric dipole transitions [2, 20, 24, 25]. There are few reports of excited state absorption measurements in $\mathrm{Nd}$ :glass systems [20, 26]. In [26] excited state absorption of the $1.06 \mu \mathrm{m}$ radiation was extracted from gain saturation measurements $\left(\sigma_{\mathrm{ex}} \approx \sigma_{\mathrm{em}} / 3\right)$, and in [19] the Judd-Ofelt theory was applied to determine the ${ }^{4} \mathrm{~F}_{3 / 2}-{ }^{2} \mathrm{G}_{9 / 2}$ oscillator strength for the excited state absorption of the $1.06 \mu \mathrm{m}$ 


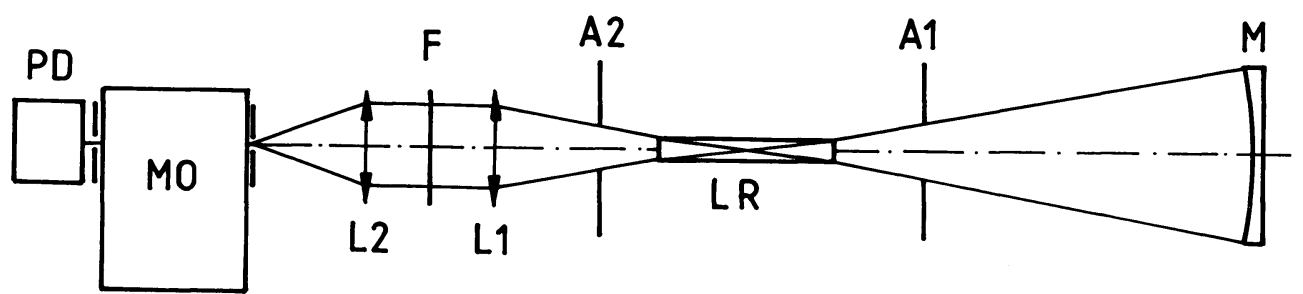

Figure 1 Experimental arrangement. LR, laser rod; $A 1, A 2$, apertures; L1, L2, lenses; F, filters; $M$, aluminium mirror; MO, monochromator; PD, PbS detector.

radiation $\left({ }^{4} \mathrm{~F}_{3 / 2}-{ }^{2} \mathrm{G}_{9 / 2}\right.$ oscillator strength is approximately equal to one tenth of ${ }^{4} \mathrm{~F}_{3 / 2}-{ }^{4} \mathrm{I}_{11 / 2}$ oscillator strength).

In this paper spontaneous emission spectra, stimulated emission cross-section spectra, and excited-state absorption cross-section spectra of some Nd:glasses (silicate glass Schott LG680, phosphate glasses Schott LG760 and Hoya LHG5) are determined by amplified spontaneous emission [4] and light amplification measurements [27]. The studies give relative cross-section distributions. Absolute cross-section distributions are obtained by calibrating the results to reported peak stimulated emission cross-sections $\sigma_{\mathrm{em}, \mathrm{P}}$ at the wavelength $\lambda_{\mathrm{P}}$ around $1.06 \mu \mathrm{m} . \sigma_{\mathrm{ex}}\left(\lambda_{\mathrm{P}}\right)$ is assumed to be zero because $\sigma_{\mathrm{em}, \mathrm{P}}$ calculations [2, 20-23] and $\sigma_{\text {eff }}\left(\lambda_{\mathrm{P}}\right)$ measurements [17-19] gave similar results within the experimental uncertainties. Deviations from $\sigma_{\mathrm{ex}}\left(\lambda_{\mathrm{P}}\right)=0$ should show up in the determined $\sigma_{\mathrm{ex}}(\lambda)$ spectra in regions of negative $\sigma_{\mathrm{ex}}$. In this case avoiding negative $\sigma_{\mathrm{ex}}$ values would allow for the determination of $\sigma_{\mathrm{ex}}\left(\lambda_{\mathrm{P}}\right)$. The ${ }^{4} \mathrm{~F}_{3 / 2}-{ }^{4} \mathrm{I}_{13 / 2},{ }^{4} \mathrm{~F}_{3 / 2}-{ }^{4} \mathrm{I}_{11 / 2}$ and ${ }^{4} \mathrm{~F}_{3 / 2}-{ }^{4} \mathrm{I}_{9 / 2}$ emission transitions are considered.

\section{Experimental details}

The experimental arrangement for the amplified spontaneous emission (ASE) and the light amplification measurements is shown in Fig. 1. The Nd:glass rod LR and two linear flash lamps (ILC Technology model L-2426) are mounted in a highly reflective double-elliptical cylinder (material is aluminium). Cooling water containing $\mathrm{NaNO}_{2}$ for ultraviolet (UV) light filtering is circulated through the pump cavity. The power supply (JK Lasers type System 2000) has a capacitor bank of $C=500 \mu \mathrm{F}$. The flash lamp pulse width is approximately $650 \mu \mathrm{s}$. The pump source allows a repetition rate of up to about $0.2 \mathrm{~Hz}$. The rod sizes are $3 / 8^{\prime \prime}$ in diameter and $4^{\prime \prime}$ in length.

In the ASE measurements the right light path is closed and the light output from the left rod surface is collected by lens L1 and transferred to the monochromator by lens L2. The monochromator output signal is detected with a PbS photoconductor (Valvo SV61). The recording wavelength is tuned manually from shot to shot. The measured signals are corrected for the wavelength dependence of the detection system. The spectral sensitivity was determined by recording the spectral distribution of a halogen-tungsten lamp of known colour temperature (Osram type HLX 64655, $T=3450 \mathrm{~K}$ at $12 \mathrm{~V}$ voltage) [28]. From the ASE spectra the spontaneous emission spectra and the stimulated emission cross-section spectra are extracted (see Section 4 below).

The light amplification is measured by feeding back the light emitted at the right side of the rod with the aid of the mirror $\mathrm{M}$ and by detecting the signal increase caused by the feedback light. The amplification is measured at a low pump voltage and a high pump 


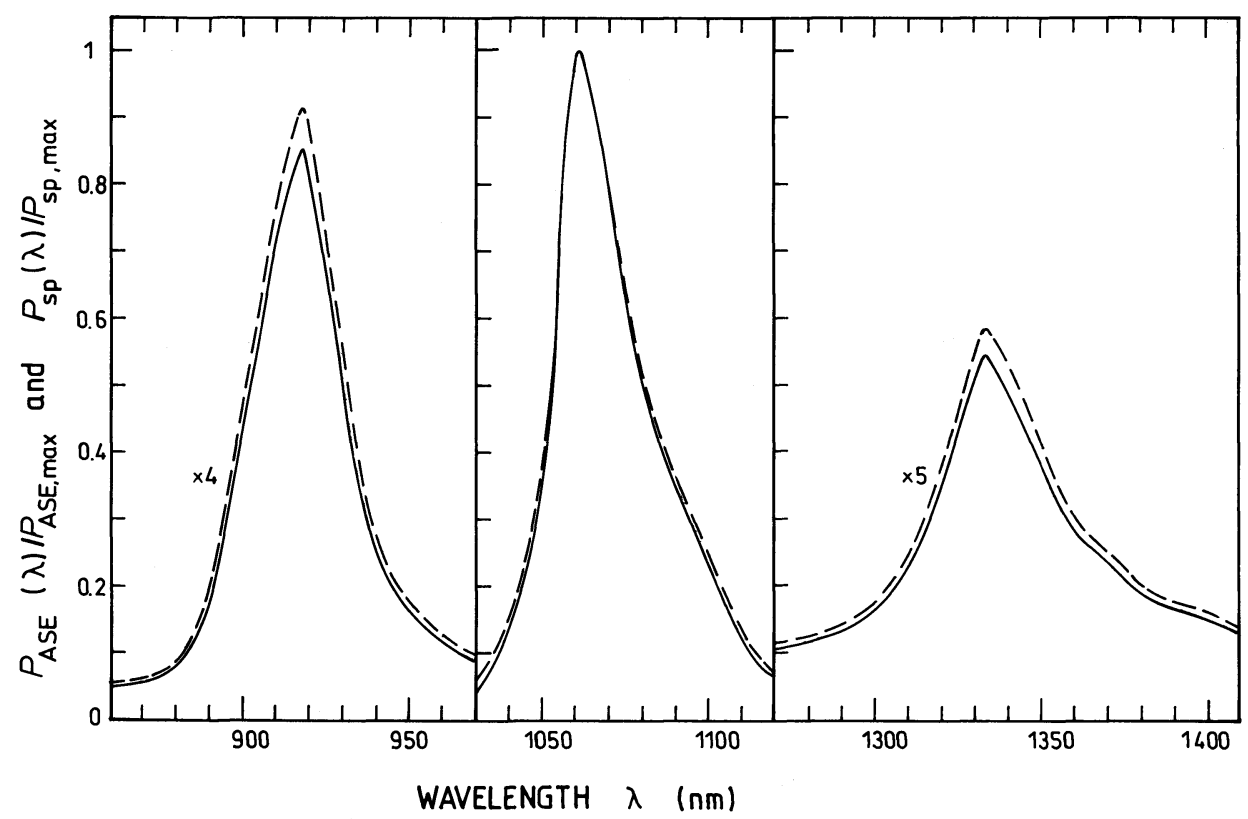

Figure 2 Normalized amplified spontaneous emission power spectra $(-)$ and normalized spontaneous emission power spectra (-- ) for silicate laser glass Schott LG680. Pump voltage $U=800 \mathrm{~V}$. The curves in the left and right figure are expanded vertically by $4 \times$ and $5 \times$, respectively.

voltage. From the amplification factor of the feedback light the effective amplification cross-section distribution $\sigma_{\mathrm{eff}}(\lambda)=\sigma_{\mathrm{em}}(\lambda)-\sigma_{\mathrm{ex}}(\lambda)$ is extracted (see Section 4 below).

\section{Experimental results}

The normalized ASE spectra $P_{\mathrm{ASE}}(\lambda) / P_{\mathrm{ASE} \text {,max }}$ of the three investigated $\mathrm{Nd}$ :glass rods are shown in Figs 2 (LG680), 3 (LG760) and 4 (LHG5). $P_{\mathrm{ASE}, \max }$ is the maximum spectral power which occurs for the ${ }^{4} \mathrm{~F}_{3 / 2}-{ }^{4} \mathrm{I}_{11 / 2}$ transition. The wavelengths $\lambda_{\mathrm{P}}$ of $P_{\text {ASE, } \max }$ (i.e. $\left.P_{\mathrm{ASE}}\left(\lambda_{\mathrm{P}}\right)=P_{\mathrm{ASE}, \max }\right)$ are $\lambda_{\mathrm{P}}=1061 \mathrm{~nm}$ for LG680 (Fig. 2), $\lambda_{\mathrm{P}}=1054 \mathrm{~nm}$ for LG760 (Fig. 3), and $\lambda_{\mathrm{P}}=1055 \mathrm{~nm}$ for LHG5 (Fig. 4). The ${ }^{4} \mathrm{~F}_{3 / 2}-{ }^{4} \mathrm{I}_{9 / 2}$ ASE spectra are Stokes shifted from the ${ }^{4} \mathrm{I}_{9 / 2}-{ }^{4} \mathrm{~F}_{3 / 2}$ absorption spectra (shown in Figs 6 to 8) because of fluorescence reabsorption by the ${ }^{4} \mathrm{I}_{9 / 2}$ ground state level population and because of thermalization of excitation within the inhomogeneously broadened ${ }^{4} \mathrm{~F}_{3 / 2}$ level.

The amplification of the light fed back to the laser rod is shown in Fig. 5 for LG680. The ${ }^{4} \mathrm{~F}_{3 / 2}-{ }^{4} \mathrm{I}_{11 / 2}$ and ${ }^{4} \mathrm{~F}_{3 / 2}-{ }^{4} \mathrm{I}_{13 / 2}$ transitions are considered. The ratio $\rho=\left(P_{\text {tot }}-P_{\mathrm{ASE}}\right) / P_{\mathrm{ASE}}$ is plotted versus wavelength for two sets of pump voltages $U_{1}=1000 \mathrm{~V}$ and $U_{2}=2000 \mathrm{~V}$. $P_{\text {tot }}$ is the total signal comprising the ASE signal $P_{\text {ASE }}$ and the amplified feedback signal. Similar curves are obtained for LG760 and LHG5. In regions of $\rho\left(\lambda, U_{2}\right)>\rho\left(\lambda, U_{1}\right)$ the feedback light is amplified in the $\operatorname{rod}\left(\sigma_{\text {eff }}(\lambda)>0\right)$, while in regions of $\rho\left(\lambda, U_{2}\right)<\rho\left(\lambda, U_{1}\right)$ the feedback light is attenuated $\left(\sigma_{\text {eff }}(\lambda)<0\right)$.

\section{Theoretical relations}

The theoretical relations between amplified spontaneous emission, light amplification, 


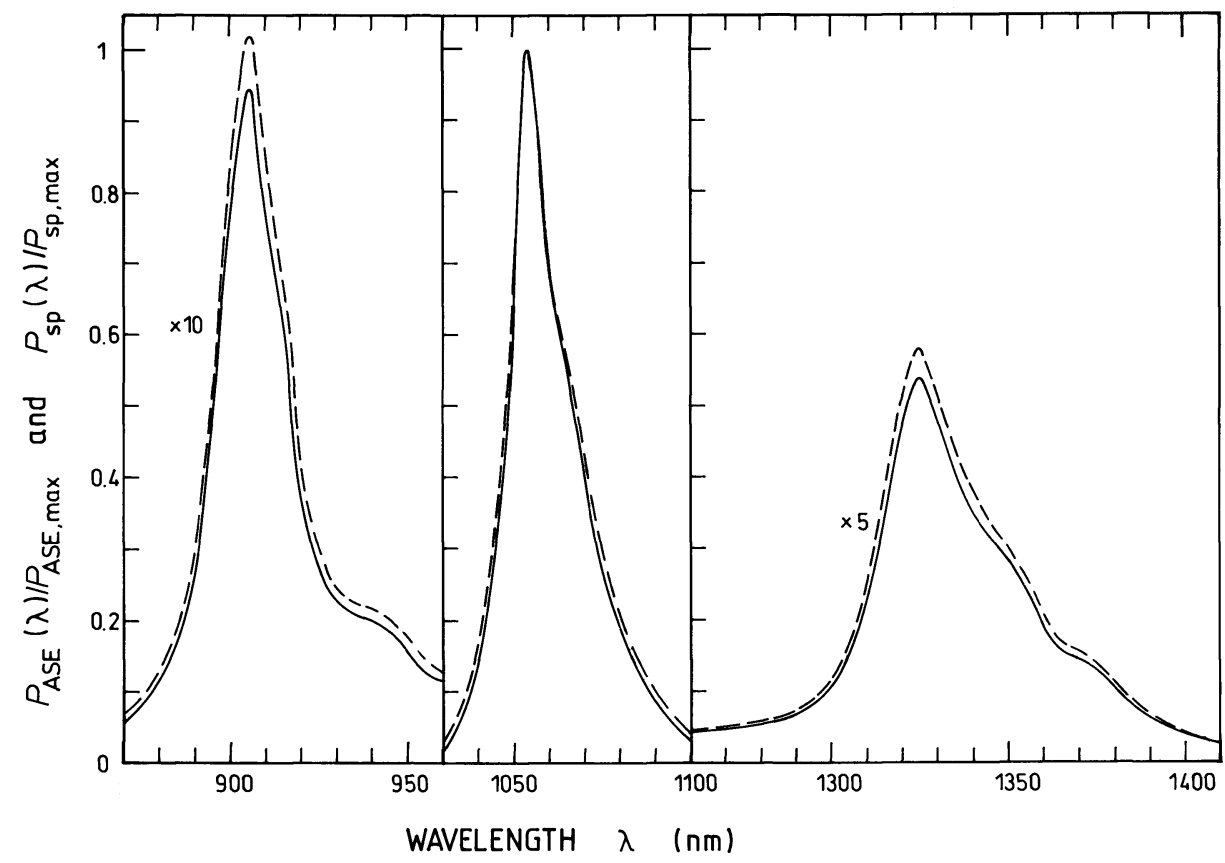

Figure 3 Normalized amplified spontaneous emission (- - ) and normalized spontaneous emission spectra $(---)$ for phosphate laser glass Schott LG760. Pump voltage $U=800 \mathrm{~V}$. The curves in the left and right figure are expanded vertically by $10 \times$ and $5 \times$, respectively.

spontaneous emission, stimulated emission cross-section, and excited-state absorption cross-section are derived in the following.

\subsection{Relation between spontaneous emission and amplified spontaneous emission}

The relation between amplified spontaneous emission power distribution $P_{\text {ASE }}(\lambda)$ and spontaneous emission power distribution $P_{\mathrm{sp}}(\lambda)$ is given by $[4,27,29]$

$$
P_{\mathrm{ASE}}(\lambda)=P_{\mathrm{sp}}(\lambda) \frac{\exp \left\{\left[\sigma_{\mathrm{em}}(\lambda)-\sigma_{\mathrm{ex}}(\lambda)\right] N_{\mathrm{u}} l\right\}-1}{\left[\sigma_{\mathrm{em}}(\lambda)-\sigma_{\mathrm{ex}}(\lambda)\right] N_{\mathrm{u}} l}
$$

In Equation 1 it is assumed that the $\mathrm{Nd}^{3+}$ excitation is constant across the rod diameter, i.e. $N_{\mathrm{u}}(r, z)=N_{\mathrm{u}}(z)$ where $r$ is the radial rod coordinate and $z$ is the axial rod coordinate. $N_{\mathrm{u}}$ is the upper laser level population number density averaged over the rod length, i.e. $N_{\mathrm{u}}=\int_{0}^{l} N_{\mathrm{u}}(z) \mathrm{d} z / l . N_{\mathrm{u}}$ depends on the flashlamp pump power, the ${ }^{4} \mathrm{~F}_{3 / 2}$ spontaneous emission lifetime and the amplification of the spontaneous emission [27, 29]. An accumulation of population in the terminal laser levels is neglected.

The gain factor $G$ of light amplification is

$$
G(\lambda)=\exp \left\{\left[\sigma_{\mathrm{em}}(\lambda)-\sigma_{\mathrm{ex}}(\lambda)\right] N_{\mathrm{u}} l\right\}
$$

Insertion of Equation 2 into Equation 1 and rearranging the terms gives

$$
P_{\mathrm{sp}}(\lambda)=P_{\mathrm{ASE}}(\lambda) \frac{\ln (G)}{G-1}
$$




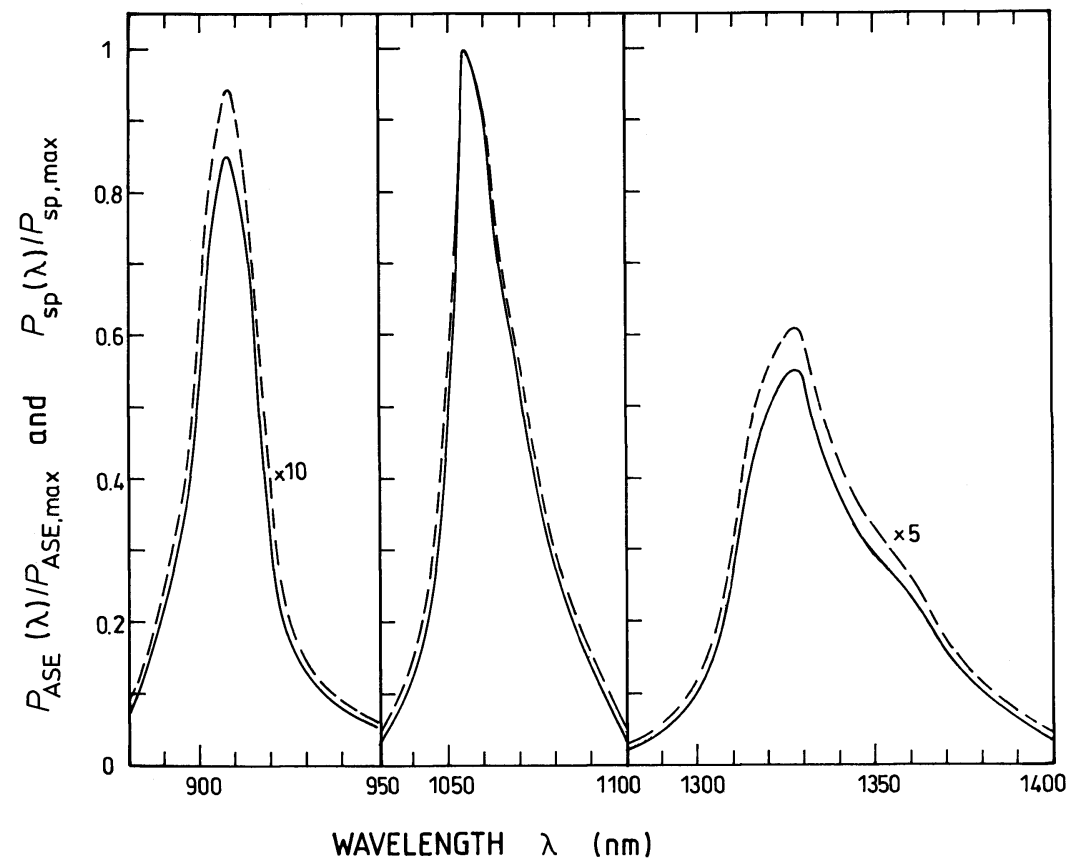

Figure 4 Normalized amplified spontaneous emission (- - and normalized spontaneous emission spectra $(---)$ for phosphate laser glass Hoya LHG5. Pump voltage $U=700 \mathrm{~V}$. The curves in the left and right figure are expanded by $10 \times$ and $5 \times$, respectively.

For weak amplification $G \rightarrow 1$ (low flashlamp pump voltage or small $\sigma_{\text {eff }}$ ) the spontaneous emission $P_{\mathrm{sp}}$ becomes equal to the amplified spontaneous emission $P_{\mathrm{ASE}}$.

\subsection{Relation between spontaneous emission and stimulated emission cross- section}

The relation between the spontaneous emission distribution $E(\lambda)=P_{\mathrm{sp}}(\lambda) / \int P_{\mathrm{sp}}(\lambda) \mathrm{d} \lambda$ (integration over all ${ }^{4} \mathrm{~F}_{3 / 2} \rightarrow{ }^{4} \mathrm{I}_{\mathrm{J}}$ transitions) and the stimulated emission cross-section distribution $\sigma_{\mathrm{em}}(\lambda)$ is $[4,20,30,31]$

$$
\sigma_{\mathrm{em}}(\lambda)=\frac{\lambda^{4} E(\lambda)}{8 \pi n^{2}(\lambda) c_{0} \tau_{\mathrm{rad}}}
$$

where $\tau_{\text {rad }}$ is the radiative lifetime of the upper laser level, $c_{0}$ is the light velocity in vacuum, and $n(\lambda)$ is the refractive index at the emission wavelength. The refractive indices at $632.8 \mathrm{~nm}$ and at the peak lasing wavelength $\lambda_{\mathrm{P}}$ around $1.06 \mu \mathrm{m}$ are given in the $\mathrm{Nd}$ :glass data sheets of Schott [32] and Hoya [33]. $n(\lambda)$ is approximately determined by applying the single oscillator dispersion relation $\left[n^{2}(\lambda)-1\right] /\left[n^{2}(\lambda)+2\right]=C /\left(\lambda_{0}^{-2}-\lambda^{-2}\right)$ where $C$ and $\lambda_{0}$ are fitting constants [34].

In our studies the stimulated emission cross-sections $\sigma_{\mathrm{em}}\left(\lambda_{\mathrm{P}}\right)$ at the peak lasing wavelength $\lambda_{\mathrm{P}}$ around $1.06 \mu \mathrm{m}$ are taken from data sheets $[32,33]$ and the spectral dependence of the stimulated emission cross-sections is calculated by

$$
\sigma_{\mathrm{em}}(\lambda)=\sigma_{\mathrm{em}}\left(\lambda_{\mathrm{P}}\right) \frac{\lambda^{4} P_{\mathrm{sp}}(\lambda) n^{2}\left(\lambda_{\mathrm{P}}\right)}{\lambda_{\mathrm{P}}^{4} P_{\mathrm{sp}}\left(\lambda_{\mathrm{P}}\right) n^{2}(\lambda)}
$$




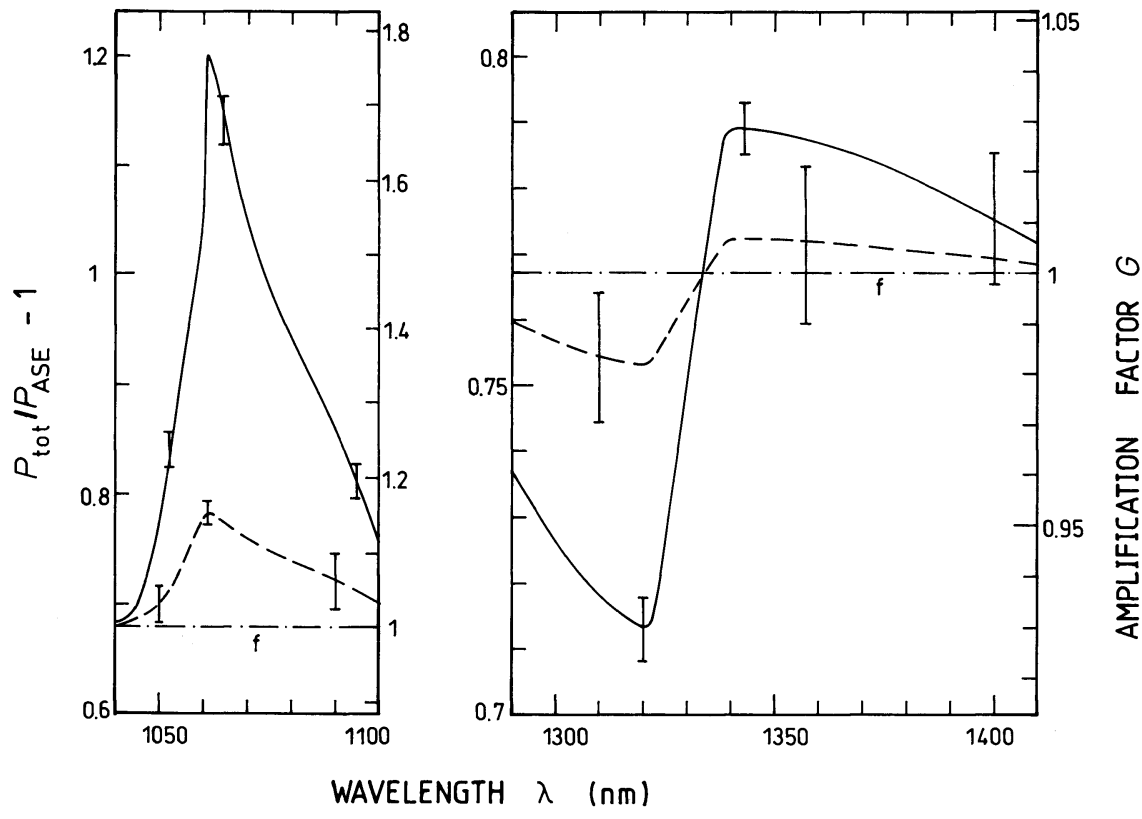

Figure 5 Normalized amplified feedback light power (left ordinates) and amplification factor $G$ (right ordinates) versus wavelength for Schott glass LG680. $U=100 \mathrm{~V}(---), U=2000 \mathrm{~V}(-)$. The $(-\cdot \cdot \cdot-\cdot-)$ curves represent the average feedback factor $f=P_{\mathrm{b} \text {, in }} / P_{\mathrm{ASE}}$ (left ordinate apply).

Equation 5 is derived by application of Equation 4 for $\sigma_{\mathrm{em}}(\lambda)$ and $\sigma_{\mathrm{em}}\left(\lambda_{\mathrm{P}}\right)$ with $E(\lambda)$ proportional to $P_{\mathrm{sp}}(\lambda)$.

Care has to be taken for the ${ }^{4} \mathrm{~F}_{3 / 2}-{ }^{4} \mathrm{I}_{9 / 2}$ transition since $P_{\mathrm{sp}}(\lambda)$ is reduced by luminescence reabsorption due to ground-state absorption. Equation 5 applies only to the long wavelength side where the thermal population of the Stark split ${ }^{4} \mathrm{I}_{9 / 2}$ levels becomes small and the luminescence reabsorption becomes weak (see Section 5).

\subsection{Amplification of feedback ASE light}

The amplification factor $G=P_{\mathrm{b}, \text { out }} / P_{\mathrm{b}, \text { in }}$ of the feedback ASE light is given by Equation 2 . The input feedback light power is $P_{\mathrm{b}, \text { in }}=f P_{\mathrm{ASE}}$ where $f$ is the feedback fraction. The amplified feedback light power is $P_{\mathrm{b}, \text { out }}=P_{\mathrm{tot}}-P_{\mathrm{ASE}}$. These relations give

$$
G(\lambda)=\frac{1}{f(\lambda)}\left[\frac{P_{\mathrm{tot}}(\lambda)}{P_{\mathrm{ASE}}(\lambda)}-1\right]=\exp \left\{\left[\sigma_{\mathrm{em}}(\lambda)-\sigma_{\mathrm{ex}}(\lambda)\right] N_{\mathrm{u}} l\right\}
$$

Knowing $\sigma_{\mathrm{em}}\left(\lambda_{\mathrm{P}}\right)-\sigma_{\mathrm{ex}}\left(\lambda_{\mathrm{P}}\right)\left(=\sigma_{\mathrm{em}}\left(\lambda_{\mathrm{P}}\right)\right.$ in our case) then $\sigma_{\mathrm{em}}(\lambda)-\sigma_{\mathrm{ex}}(\lambda)$ may be expressed by

$$
\sigma_{\mathrm{em}}(\lambda)-\sigma_{\mathrm{ex}}(\lambda)=\left[\sigma_{\mathrm{em}}\left(\lambda_{\mathrm{P}}\right)-\sigma_{\mathrm{ex}}\left(\lambda_{\mathrm{P}}\right)\right] \frac{\ln \left\{\frac{1}{f(\lambda)}\left[\frac{P_{\mathrm{tot}}(\lambda)}{P_{\mathrm{ASE}}(\lambda)}-1\right]\right\}}{\ln \left\{\frac{1}{f\left(\lambda_{\mathrm{P}}\right)}\left[\frac{P_{\mathrm{tot}}\left(\lambda_{\mathrm{P}}\right)}{P_{\mathrm{ASE}}\left(\lambda_{\mathrm{P}}\right)}-1\right]\right\}}
$$

The determination of $\sigma_{\mathrm{em}}(\lambda)-\sigma_{\mathrm{ex}}(\lambda)$ relative to $\sigma_{\mathrm{em}}\left(\lambda_{\mathrm{p}}\right)-\sigma_{\mathrm{ex}}\left(\lambda_{\mathrm{P}}\right)$ avoids the necessity to determine $N_{\mathrm{u}}$ explicitly. 


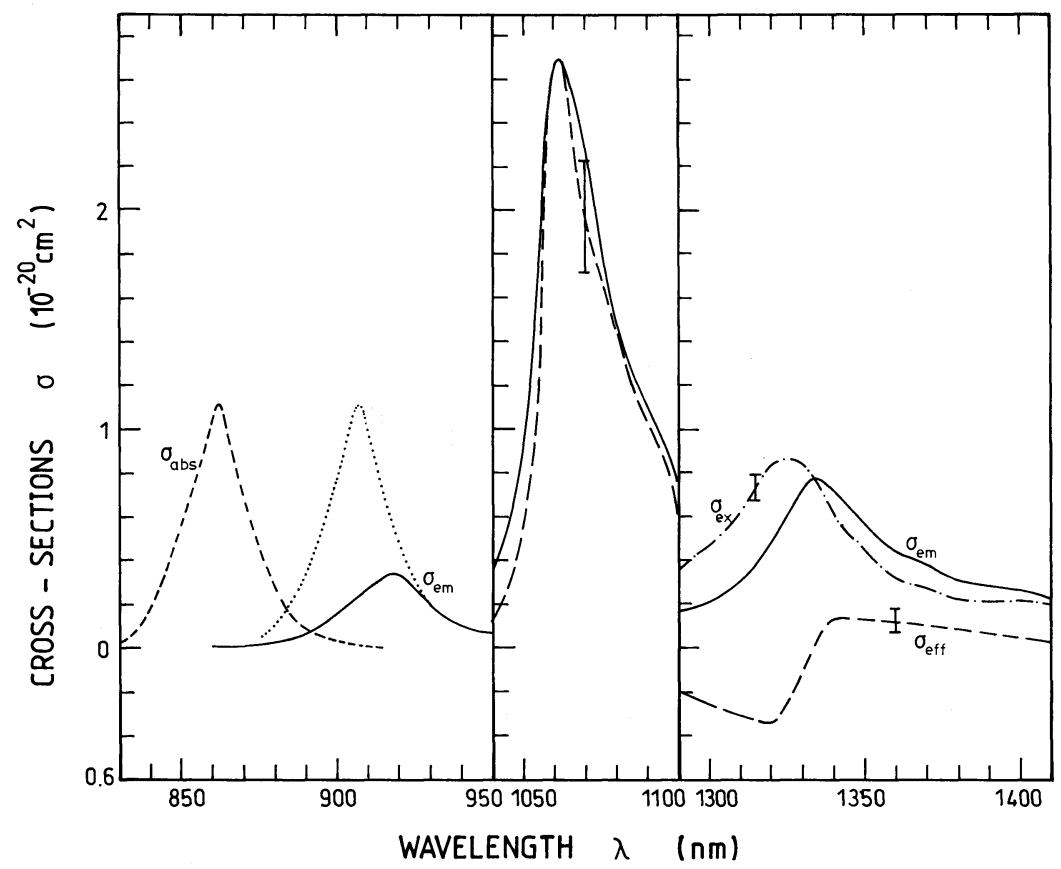

Figure 6 Cross-sections of Schott Glass LG680. Curves are calibrated to $\sigma_{\mathrm{em}, \mathrm{P}}=\sigma_{\mathrm{em}}\left(\lambda_{\mathrm{P}}\right)=2.9 \times 10^{-20} \mathrm{~cm}^{2}$ with $\lambda_{\mathrm{P}}=1061 \mathrm{~nm}$ [32]. $\sigma_{\mathrm{ex}}\left(\lambda_{\mathrm{P}}\right)=0$ is assumed. Absorption spectrum $\sigma_{\mathrm{abs}}(\lambda)$ is calculated from transmission spectrum in [32].

The feedback fraction $f(\lambda)$ is nearly wavelength-independent. Assuming a linear relation between the upper laser level population $N_{\mathrm{u}}$ and the square of the flashlamp pump voltage $U$, the feedback fraction $f(\lambda)$ may be determined from Equation 6 by the following relation:

$$
f(\lambda)=\left[\frac{P_{\text {tot }}\left(\lambda, U_{1}\right)}{P_{\mathrm{ASE}}\left(\lambda, U_{1}\right)}-1\right] \exp \left[-\kappa(\lambda) U_{1}^{2}\right]
$$

where $\kappa(\lambda) U^{2}=\left[\sigma_{\mathrm{em}}(\lambda)-\sigma_{\mathrm{ex}}(\lambda)\right] N_{\mathrm{u}}(U) l=\ln [G(\lambda, U)] . \kappa(\lambda)$ may be expressed by

$$
\begin{aligned}
\kappa(\lambda) & =\frac{\ln \left[G\left(\lambda, U_{2}\right)\right]-\ln \left[G\left(\lambda, U_{1}\right)\right]}{U_{2}^{2}-U_{1}^{2}} \\
& =\frac{\ln \left[P_{\mathrm{tot}}\left(\lambda, U_{2}\right) / P_{\mathrm{ASE}}\left(\lambda, U_{2}\right)-1\right]-\ln \left[P_{\mathrm{tot}}\left(\lambda, U_{1}\right) / P_{\mathrm{ASE}}\left(\lambda, U_{1}\right)-1\right]}{U_{2}^{2}-U_{1}^{2}}
\end{aligned}
$$

For small pump voltages $f(\lambda)$ approaches $\left[P_{\text {tot }}(\lambda, U \rightarrow 0) / P_{\mathrm{ASE}}(\lambda, U \rightarrow 0)\right]-1$. Within the ${ }^{4} \mathrm{~F}_{3 / 2}-{ }^{4} \mathrm{I}_{13 / 2}$ and the ${ }^{4} \mathrm{~F}_{3 / 2}-{ }^{4} \mathrm{I}_{11 / 2}$ emission bands average $f(\lambda)$ values are used.

The analysis described above is not applicable to the ${ }^{4} \mathrm{~F}_{3 / 2}-{ }^{4} \mathrm{I}_{9 / 2}$ transition because ground-state light absorption has not been included. For this case Equation 2 has to be rewritten to

$$
G(\lambda)=\exp \left\{\left[\sigma_{\mathrm{em}}(\lambda)-\sigma_{\mathrm{ex}}(\lambda)\right] N_{\mathrm{u}} l-\sigma_{\mathrm{abs}}(\lambda) N_{\mathrm{g}} l\right\}
$$

where $\sigma_{\text {abs }}(\lambda)$ is the ${ }^{4} \mathrm{I}_{9 / 2}-{ }^{4} \mathrm{~F}_{3 / 2}$ ground-state absorption cross-section and $N_{\mathrm{g}}$ is the ${ }^{4} \mathrm{I}_{9 / 2}$ ground-state level population. Net gain $G>1$ requires $N_{\mathrm{u}}>N_{\mathrm{g}} \sigma_{\mathrm{abs}}(\lambda) /\left[\sigma_{\mathrm{em}}(\lambda)-\sigma_{\mathrm{ex}}(\lambda)\right]$ as in three-level laser systems [4]. 


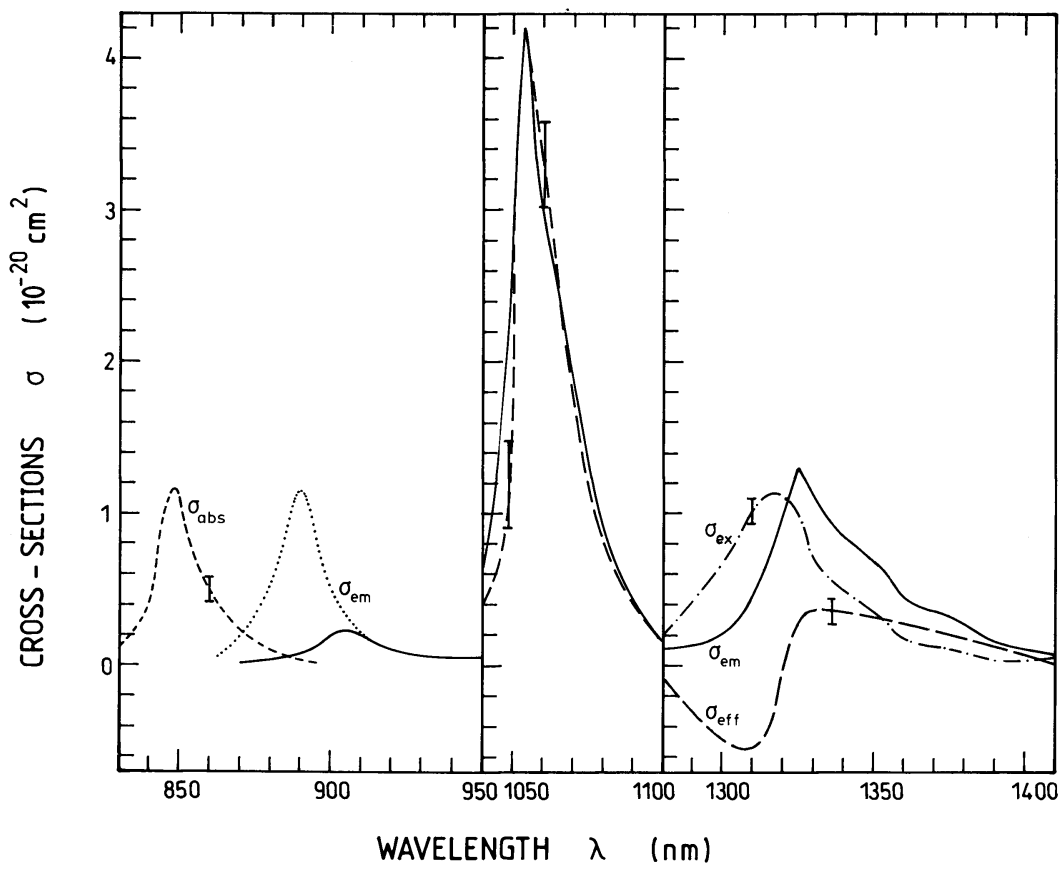

Figure 7 Cross-sections of Schott Glass LG760. Curves are calibrated to $\sigma_{\mathrm{em}}\left(\lambda_{\mathrm{P}}\right)=4.2 \times 10^{-20} \mathrm{~cm}^{2}$ $\left(\lambda_{\mathrm{P}}=1053.5 \mathrm{~nm}[32]\right), \sigma_{\mathrm{ex}}\left(\lambda_{\mathrm{P}}\right)=0$ is assumed. $\sigma_{\mathrm{abs}}(\lambda)$ is calculated from transmission spectrum in [32].

\section{Theoretical results}

Average feedback factors $f$ are determined from the $\left(P_{\mathrm{tot}}-P_{\mathrm{ASE}}\right) / P_{\mathrm{ASE}}$ curves by application of Equations 8 and 9. They are shown by the dash-dotted lines in Fig. 5 for LG680. Using the right ordinates of Fig. 5 the dashed and solid curves present the gain curves $G=\left(P_{\text {tot }}-P_{\mathrm{ASE}}\right) /\left(P_{\mathrm{ASE}} f\right)$ for the pump voltages of $1000 \mathrm{~V}$ (dashed) and $2000 \mathrm{~V}$ (solid). $G>1$ represents dominant amplification and $G<1$ represents dominant attenuation.

Knowing $G(\lambda, U)$, the $P_{\mathrm{ASE}}(\lambda) / P_{\mathrm{ASE}, \max }$ curves of Figs 3 and 4 (solid curves) may be transferred to $P_{\mathrm{sp}}(\lambda) / P_{\text {sp, } \max }$ curves by application of Equation 3 . They are shown by the dashed curves in Figs 2, 3 and 4. The spectral narrowing of the ASE curves compared to the spontaneous emission curves is small because the gain $G\left(\lambda_{\mathrm{P}}\right)$ is small for displayed ASE $\operatorname{spectra}\left(G\left(\lambda_{\mathrm{P}}, 800 \mathrm{~V}\right) \approx 1.1\right.$ for LG680, $G\left(\lambda_{\mathrm{p}}, 800 \mathrm{~V}\right) \approx 1.25$ for LG760, and $G\left(\lambda_{\mathrm{p}}, 700 \mathrm{~V}\right) \approx$ 1.19 for LHG5). The ${ }^{4} \mathrm{~F}_{3 / 2}-{ }^{4} \mathrm{I}_{13 / 2}$ fluorescence peaks around $1330 \mathrm{~nm}$ are approximately a factor of 9.3 smaller than the ${ }^{4} \mathrm{~F}_{3 / 2}-{ }^{4} \mathrm{I}_{11 / 2}$ fluorescence peaks $P_{\mathrm{sp}, \max }$ at $\lambda_{\mathrm{P}}$ around $1055 \mathrm{~nm}$ for all three investigated $\mathrm{Nd}$ :glass rods. The ${ }^{4} \mathrm{~F}_{3 / 2}-{ }^{4} \mathrm{I}_{9 / 2}$ fluorescence peaks of the phosphate laser rods LG760 and LHG5 occur around $907 \mathrm{~nm}$ and are approximately a factor of 11 smaller than $P_{\text {sp,max }}$, while the ${ }^{4} \mathrm{~F}_{3 / 2}{ }^{4} \mathrm{I}_{9 / 2}$ fluorescence peak of the silicate laser rod LG680 is located at $918 \mathrm{~nm}$ and its relative height is $P_{\mathrm{sp}}(918 \mathrm{~nm}) / P_{\mathrm{sp}, \max }=0.21$.

The stimulated emission cross-sections $\sigma_{\mathrm{em}}(\lambda)$ are derived from Equation 5 and are displayed by the solid curves in Figs 6, 7 and 8 for the laser glasses LG680, LG760 and LHG5, respectively. The curves are adjusted to the $\sigma_{\mathrm{em}}\left(\lambda_{\mathrm{P}}\right)$ values of the data sheets $[32,33]$. For the ${ }^{4} \mathrm{~F}_{3 / 2}-{ }^{4} \mathrm{I}_{9 / 2}$ transition only the long-wavelength part of the solid curves $(\lambda \gtrsim 930 \mathrm{~nm}$ for LG680, $\lambda \gtrsim 910 \mathrm{~nm}$ for LG760 and LHG5) gives correct $\sigma_{\mathrm{em}}$ values. The dotted curves show 


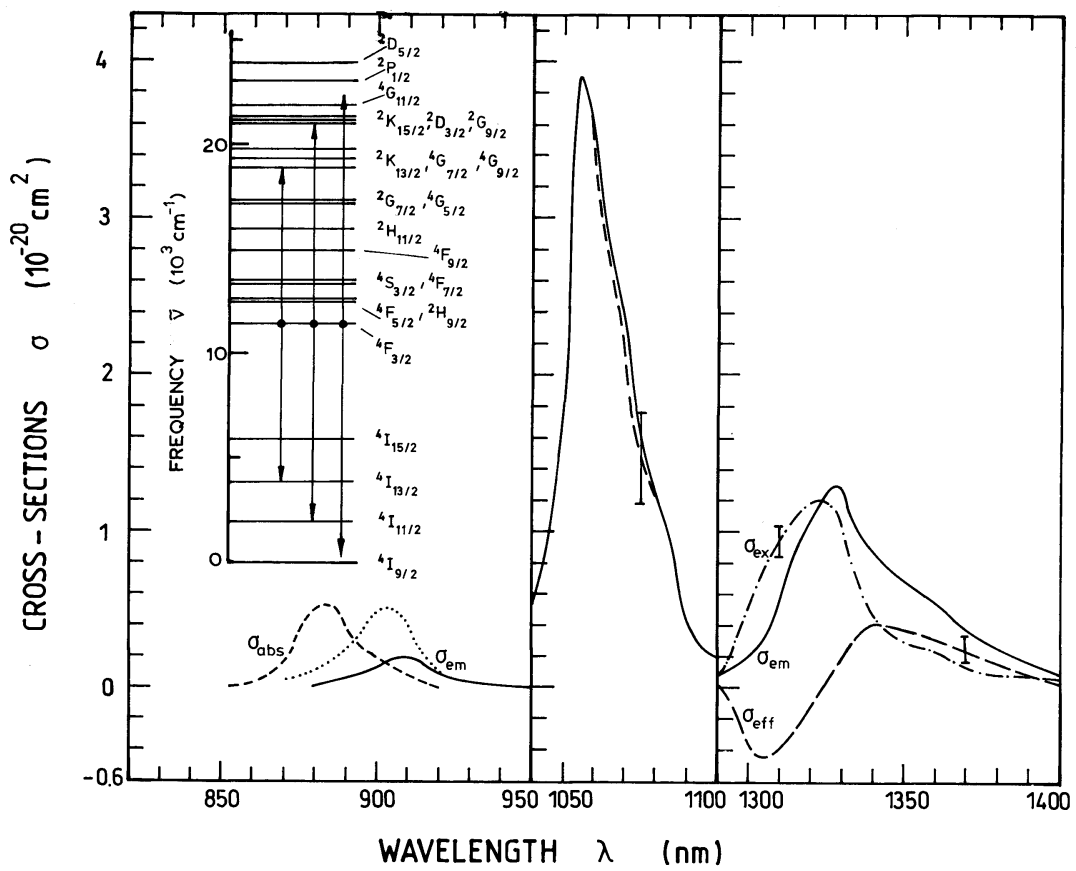

Figure 8 Cross-sections of Hoya Glass LHG5. Curves are calibrated to $\sigma_{\text {em }}\left(\lambda_{\mathrm{P}}\right)=3.9 \times 10^{-20} \mathrm{~cm}^{2}$ $\left(\lambda_{\mathrm{p}}=1054 \mathrm{~nm}\right.$ in [33]), $\sigma_{\mathrm{ex}}\left(\lambda_{\mathrm{p}}\right)=0$ is assumed. $\sigma_{\mathrm{abs}}(\lambda)$ is redrawn from [35]. The inserted level diagram is redrawn from [2].

the expected wavelength dependence of $\sigma_{\mathrm{em}}$. They are drawn by assuming a mirror symmetry between $\sigma_{\mathrm{em}}$ and $\sigma_{\mathrm{abs}}[5,31]$. The ${ }^{4} \mathrm{~F}_{3 / 2}{ }^{4} \mathrm{I}_{9 / 2}$ absorption spectra are shown by the short-dashed curves. They are calculated from transmission spectra displayed in [32] for the Schott glasses LG680 and LG760 and from an optical density spectrum of LHG5 given in [35].

The $\sigma_{\text {eff }}(\lambda)$ curves are derived from Equation 7 and are displayed by the dashed curves in the Figs 6 to $8 . \sigma_{\text {ex }}\left(\lambda_{\mathrm{P}}\right)=0$ is assumed. For the ${ }^{4} \mathrm{~F}_{3 / 2}-{ }^{4} \mathbf{I}_{9 / 2}$ transitions the $\sigma_{\text {eff }}$ spectra are not shown because of the ground state light absorption. The difference of $\sigma_{\mathrm{em}}(\lambda)-\sigma_{\mathrm{eff}}(\lambda)$ gives the excited state absorption cross-section. For the ${ }^{4} \mathrm{~F}_{3 / 2}-{ }^{4} \mathrm{I}_{13 / 2}$ transitions around $1.32 \mu \mathrm{m}$ the $\sigma_{\mathrm{ex}}(\lambda)$ spectra are shown by the dash-dotted curves.

The excited state absorption cross-sections are remarkably large in the region of the peak stimulated emission cross-section of the ${ }^{4} \mathrm{~F}_{3 / 2}{ }^{4} \mathrm{I}_{13 / 2}$ transition. This finding is in agreement with the observation of a long-wavelength shift of laser action to the region between $1.35 \mu \mathrm{m}$ and $1.40 \mu \mathrm{m}$ [7-9] while the peak of spontaneous emission is between $1.325 \mu \mathrm{m}$ and $1.335 \mu \mathrm{m}$. The excited state absorption is due to transitions from the ${ }^{4} \mathrm{~F}_{3 / 2}$ level to the ${ }^{2} \mathrm{~K}_{13 / 2}$, ${ }^{4} \mathrm{G}_{7 / 2}$, and ${ }^{4} \mathrm{G}_{9 / 2}$ levels as is seen by the level diagram inserted in Fig. 8. The strong excited state absorption around $1.32 \mu \mathrm{m}$ is unfavourable for the application of $\mathrm{Nd}$ :glass lasers on the ${ }^{4} \mathrm{~F}_{3 / 2}{ }^{4} \mathrm{I}_{13 / 2}$ transition.

The $\sigma_{\text {eff }}(\lambda)$ and $\sigma_{\mathrm{em}}(\lambda)$ curves for the ${ }^{4} \mathrm{~F}_{3 / 2}-{ }^{4} \mathrm{I}_{11 / 2}$ transition around $1.06 \mu \mathrm{m}$ agree within the uncertainties. The peak heights at $\lambda_{\mathrm{p}}$ are adjusted to the same value. $\sigma_{\text {ex }}(\lambda)$ values up to about $20 \%$ of the $\sigma_{\mathrm{em}}\left(\lambda_{\mathrm{P}}\right)$ values cannot be excluded because the assumption $\sigma_{\mathrm{ex}}\left(\lambda_{\mathrm{P}}\right)=0$ is only valid within this limit $[20,26]$ and the deviations between $\sigma_{\mathrm{em}}$ and $\sigma_{\mathrm{eff}}$ are of this order. 
The ground-state absorption occurring for the ${ }^{4} \mathrm{~F}_{3 / 2}-{ }^{4} \mathrm{I}_{9 / 2}$ transition hinders a determination of $\sigma_{\text {eff }}(\lambda)$ and $\sigma_{\text {ex }}(\lambda)$. The $\sigma_{\text {em }}(\lambda)$ distributions could be determined roughly from the ${ }^{4} \mathrm{~F}_{3 / 2}-{ }^{4} \mathrm{I}_{9 / 2}$ absorption spectra. Laser action on the ${ }^{4} \mathrm{~F}_{3 / 2}-{ }^{4} \mathrm{I}_{9 / 2}$ transmission seems to be possible under strong pumping conditions as they are necessary for three-level laser systems $[4,5]$.

\section{Conclusions}

Stimulated emission cross-section, $\sigma_{\mathrm{em}}$, and excited-state absorption cross-section, $\sigma_{\mathrm{ex}}$, distributions for neodymium doped glasses have been determined by amplified spontaneous emisssion and light amplification measurements of flashlamp pumped rods. The obtained effective stimulated emission cross-section curves, $\sigma_{\mathrm{eff}}=\sigma_{\mathrm{em}}-\sigma_{\mathrm{ex}}$, give a clear indication of the possible lasing regions of the glass rods. The described measurement technique may also be applied to other solid-state laser materials employing four-level laser transitions.

The absolute peak stimulated emission cross-sections, $\sigma_{\mathrm{em}}\left(\lambda_{\mathrm{P}}\right)$, were taken from the literature. If additionally the radiative lifetime, $\tau_{\mathrm{rad}}$, of the upper laser level is determined (see Equation 4 [31]), e.g. by fluorescence lifetime, $\tau_{\mathrm{F}}$, and fluorescence quantum yield, $\phi_{\mathrm{F}}$, measurement $\left(\tau_{\mathrm{rad}}=\tau_{\mathrm{F}} / \phi_{\mathrm{F}}\right)$, then absolute $\sigma_{\mathrm{em}}(\lambda)$ curves are obtainable.

\section{Acknowledgements}

The authors thank the Deutsche Forschungsgemeinschaft for financial support.

\section{References}

1. A. A. KAMINSKII, 'Laser Crystals their Physics and Properties', Springer Series in Optical Sciences, Vol. 14 (Springer-Verlag, Berlin, 1981).

2. D. C. BROWN, 'High-Peak Power Nd:Glass Systems', Springer Series in Optical Sciences, Vol. 25 (SpringerVerlag, Berlin, 1981).

3. S. E. STOKOWSKI, in CRC 'Handbook of Laser Science of Technology', Vol. 1, Lasers and Masers, edited by M. J. Weber (CRC Press, Florida, 1982) p. 215.

4. A. PENZKOFER, Prog. Quantum Electron. 12 (1988) 291.

5. W. KOECHNER, 'Solid-State Laser Engineering', Springer Series in Optical Sciences, Vol. 1, 2nd edition (Springer-Verlag, Berlin, 1988).

6. P. F. MOULTON, in CRC 'Handbook of Laser Science and Technology', Vol. 1, Lasers and Masers, edited by M. J. Weber (CRC Press, Florida, 1982) p. 21.

7. P. B. MAUER, Appl. Opt. 3 (1964) 153.

8. A. D. PEARSON, S. P. S. PORTO and W. R. NORThOVER, J. Appl. Phys. 35 (1964) 1704.

9. A. A. KAMINSKII, S. E. SARKISOV, T. NGOC, B. I. DENKER, V. V. OSIKO and A. M. PROKHOROV, Phys. Stat. Sol. A50 (1978) 745.

10. E. F. ARTeM'eV, A. G. MUrzin and V. A. Fromzel, Sov. Phys. Tech. Phys. 22 (1977) 274.

11. R. D. MAURER, Appl. Opt. 2 (1963) 87.

12. O. D. GAVRilov, A. A. MAK, D. S. PRILEZHAEV, V. I. USTYUGOV and V. A. FrOMZEL, Opt. Spektrosk. 34 (1973) 141.

13. L. A. LOMPre, G. MAinfray and J. Thebault, J. Appl. Phys. 48 (1977) 1570.

14. H. SCHILlinger and A. PENZKOFER, Opt. Commun. 68 (1988) 45.

15. J. FURTHNER, H. SCHILLINGER and A. PENZKOFER, ibid., 78 (1990) 41.

16. U. CZARNETZKI and V. SCHULZ VON DER GATHEN, Appl. Opt. 25 (1986) 2912.

17. J. G. EDWARDS, Brit. J. Appl. Phys. (J. Phys. D) 1 (1968) 449.

18. M. BIRNBAUM and J. A. GElbWACHS, J. Appl. Phys. 43 (1972) 2335.

19. A. W. TUCKER, M. BIRNBAUM and C. L. FINCHER, ibid., 53 (1982) 161.

20. W. F. KRUPKE, IEEE J. Quantum Electron. QE-10 (1974) 450.

21. R. R. JACOBS and M. J. WEBER, ibid., QE-11 (1975) 846.

22. R. R. JACOBS and M. J. WEBER, ibid., QE-12 (1976) 102.

23. G. J. LUIFORD, R. A. SAROYAN, J. B. TRENHOLME and M. J. WEBER, ibid., QE-15 (1979) 510. 
24. B. R. JUDD, Phys. Rev. 127 (1962) 750.

25. G. S. OFELT, J. Chem. Phys. 37 (1962) 511.

26. M. E. VANCE, IEEE J. Quantum Electron. QE-6 (1970) 249.

27. P. SPERBER, W. SPANGLER, B. MEIER and A. PENZKOFER, Opt. Quantum Electron. 20 (1988) 395.

28. W. BÄUMLER and A. PENZKOFER, Chem. Phys. 140 (1990) 75.

29. P. SPERBER, M. WEIDNER and A. PENZKOFER, Appl. Phys. B42 (1987) 185.

30. A. V. DESHPANDE, A. BEIDOUN, A. PENZKOFER and G. WAGENBlAST, Chem. Phys. 142 (1990) 123.

31. O. G. PETERSON, J. P. WEBB, W. C. MCCOLGIN and J. H. EBERLY, J. Appl. Phys. 42 (1971) 1917.

32. Laser Glass, data sheet 2301/88 (printed in USA, 1988), From Schott Glaswerke, Optics division, Mainz, Fed. Rep. Germany.

33. Hoya Laser Glasses, data sheet May 1982-500 (printed in Japan, 1982) from Hoya Corporation, Optical division, Tokyo, Japan.

34. A. PENZKOFER, H. GLAS and J. SCHMAilzL, Chem. Phys. 70 (1982) 47.

35. L. I. AVOKYANTS, I. M. BUZHINSKII, E. I. KORYAGINA and V. F. SURKOV, Sov. J. Quantum Electron. 8 (1978) 423. 